\title{
Reassessing the financial and social costs of public transport
}

Xucheng Li BEng

PhD Student, Faculty of Engineering and the Environment, University of Southampton, Southampton, UK
John Preston BA, MA, PhD, MCILT, FRGS, FCIHT,

Head of Civil, Maritime and Environmental Engineering and Science, Faculty of Engineering and the Environment, University of Southampton, Southampton, UK

Increasing urbanisation around the world has raised the passenger demand for public transport. Many public transport technologies are available to meet this demand. This paper develops a spreadsheet cost model that simulates public transport modes operated on a 12-km route and incorporates a new public transport mode, the straddle bus. Previous research has assumed that demand is exogenous (externally fixed). This work investigates the impact of endogenous demand, which varies with service level characteristics. Elasticities for passenger waiting time and in-vehicle time are used to assess actual passenger reactions to the attractiveness for different public transport technologies at different levels of demand. The result of this work shows the lowest average social and operator cost public transport technologies for different ranges of demand. Based on the default values used in the spreadsheet model, smaller size vehicles (e.g. personal rapid transit and minibus) dominate the low passenger demand range due to their short waiting times. Single-decker and double-decker buses appear to be the best option for a demand of around 3000-60000 passengers per day (ppd), followed by the straddle bus (from around 60000 to 100000 ppd). The great capacity but high capital costs of underground make it the most cost-effective technology when other technologies are experiencing high congestion, with demand levels higher than 100000 ppd.

\section{Introduction}

The rapid development of modern society has made people more reliant on transport technologies for a variety of journey purposes such as commuting, shopping and education. Passenger journeys on local bus services in the UK in 2010 have increased by approximately $13 \%$ since $2004 / 05$. The annual passenger revenues of light rail and tram systems have increased by $19 \%$ over the same period while the passenger kilometres travelled by national rail have doubled since privatisation (1994/1995) (DfT, 2012). Related to the increasing demand for public transport, many innovative and intermediate modes have been developed to suit various passenger requirements. A few examples are shown in Table 1.

Different types of public transport would have better feasibility at distinct demand levels, and the costs would also vary. Therefore, comparing their costs in the same situation to select the most appropriate mode is an essential issue. The cost of public transport technologies consists of not only the costs of operators (which may be transferred on to passengers in terms of fares) but also the costs borne by society in general (Jakob et al., 2006), which is the total social cost.

Comparisons between different public transport services have been undertaken in many previous studies. Meyer et al. (1965) did the pioneering study in this area and investigated line-haul operator costs for different transport modes (rail, bus and linehaul auto) on a single distinct route in different population density areas. They found that an automobile system with only
1.6 passengers in each car could cost less at low corridor volumes (less than 5000 hourly passenger requirement). Rail systems are very cost effective when population densities are high and journeys are short and therefore rail costs least in high population density areas while bus systems do better in low and medium population density areas.

The TEST (Tools for evaluating strategically integrated public transport) project was carried out by Brand and Preston (2001, 2002a, 2002b, 2003a, 2003b, 2006) to compare different forms of public transport by using the average and marginal social costs, which include user costs and external costs rather than just the costs for the operator. The work developed a stand-alone spreadsheet model in Microsoft Excel to investigate the relationship between demand levels and social costs, and a more detailed integrated model using transport analysis software Vips (now part of the wider Visum model) and Contram to compare the user benefits from the spreadsheet model. By considering the steady operating period in a day for a $12-\mathrm{km}$ public transport route, Brand and Preston (2006) found that the social costs of public transport are closely linked with the daily demand level if it is externally fixed. For example, bus technologies demonstrate their significant advantages in the low average daily demand range (less than 40000 passengers per day (ppd)) by having less social cost per passenger, suburban heavy rail becomes most cost effective between 40000 and 84000 ppd and regional heavy rail has the lowest average social cost after that. Tirachini et al. (2010) developed a model to compare operator costs and user costs of light rail, heavy rail and bus rapid transit (BRT) in a 


\begin{tabular}{|c|c|c|}
\hline Technology & Example & Features \\
\hline PRT & $\begin{array}{l}\text { London Heathrow airport ULTra PRT } \\
\text { system (ULTraGlobalPRT, 2011) }\end{array}$ & $\begin{array}{l}\text { Demand-responsive transport } \\
\text { High operating speed due to segregated track } \\
\text { Low passenger capacity and high infrastructure costs }\end{array}$ \\
\hline Guided bus & $\begin{array}{l}\text { Leeds Superbus guided bus system } \\
\text { (Currie and Wallis, 2008) }\end{array}$ & $\begin{array}{l}\text { Ensures punctuality and reliability compared with conventional bus } \\
\text { services } \\
\text { Higher infrastructure costs compared with conventional bus services } \\
\text { Reduces journey time by } 33 \% \text { and increases } 40 \% \text { patronage } \\
\text { Medium passenger capacity }\end{array}$ \\
\hline Modern light rail & $\begin{array}{l}\text { Manchester Metrolink (Knowles, } \\
\text { 2007) }\end{array}$ & $\begin{array}{l}\text { More frequent services and cheaper fares than national rail } \\
\text { Better operating speed and punctuality than conventional bus services } \\
\text { Infrastructure costs higher than conventional buses but lower than } \\
\text { heavy rail } \\
\text { High passenger capacity }\end{array}$ \\
\hline Straddle bus & Conceptual (McDermon, 2010) & $\begin{array}{l}\text { Shares lanes with general traffic while operating above the traffic } \\
\text { Lower infrastructure costs than heavy rail technology } \\
\text { Requires less space and has higher capacity than conventional buses } \\
\text { while avoiding congestion of general traffic }\end{array}$ \\
\hline
\end{tabular}

Table 1. Examples of different intermediate public transport technologies

radial transport network. Their research identified the conditions under which BRT costs less than light rail and heavy rail in a radial network by considering four key elements: access time cost, waiting time cost, in-vehicle time cost and operator cost including land and infrastructure capital costs. According to their work, BRT would be able to provide the lowest total cost for all demand ranges if the operating speed of light rail and heavy rail was less than $5 \mathrm{~km} / \mathrm{h}$ and $9 \mathrm{~km} / \mathrm{h}$ faster, respectively, than BRT.

However, the demand level increments in these models are all externally fixed, which means the results are all based on fixed demand prediction. In reality, passenger demand levels are endogenous, not exogenous, and are affected by the performance of the public transport technologies such as the service interval and journey time. The actual average costs could be substantially different if the model only considers the fixed demand level because the actual passenger demand could vary due to the quality of service.

Therefore, the objectives of this paper are, firstly, to improve the comparison spreadsheet model for different public transport modes developed by Brand and Preston (2006) by investigating the endogenous relationship between demand and supply to ensure the average cost reflects the actual traffic condition with correct demand level. Secondly, as an illustration of the capability of the spreadsheet model to examine new public transport technologies, the straddle bus is added into the spreadsheet model. Thirdly, the cost data in the previous study are updated from 2000 prices to 2011 prices. Furthermore, demand elasticities for passenger travel time and waiting time are also taken into account to calculate the impact of different service levels on passenger demand levels.

The organisation of the paper is as follows. Section 2 demonstrates how the spreadsheet model works and what improvements have been made compared with the spreadsheet model of Brand and Preston (2006). Section 3 presents the key results obtained from the developed spreadsheet model. Section 4 concludes with the main outcomes from this study and then recommends potential future work.

\section{The spreadsheet model}

The spreadsheet model developed in the TEST project by Brand and Preston (2006) was based on the study of social costs by Jansson (1980), who developed the concept of social costs as the sum of total producer costs and total user costs, and the work on operator costs by Meyer et al. (1965), who developed an equation for total operator and other non-structural costs of rail and bus transit.

\subsection{Assumptions and equations}

The TEST project developed total social costs (TSCs) as the sum of total operator costs (TOCs), total user costs (TUCs) and total external costs (TECs)

$\mathrm{TSC}=\mathrm{TOC}+\mathrm{TUC}+\mathrm{TEC}$ 
where TOC covers all capital investment by operators of the public transport service, the TUC includes passenger walking time, waiting time and in-vehicle time converted into money units using values of time and the TEC accounts for any external impacts such as air pollution and accidents.

There are a number of assumptions made in the TEST model. The TEST model is based on the core operating day time services (07:00 to 18:00). Three time periods have been identified in this model - morning peak, evening peak and off-peak period. The lengths of these time sectors are assumed to be $2 \mathrm{~h}$ for each peak time and $7 \mathrm{~h}$ for the off-peak, giving $11 \mathrm{~h}$ of steady operating period in total. The daily passenger demands are split into these time periods, which are $22.5 \%$ for each peak period and $55 \%$ for the off-peak. Model calculations are based on the input of estimated demand and parameters of the public transport technologies and are either set by the user or the default values can be used. With initial input data, the model can then obtain the intermediate outputs such as required service frequency and average operational speed, which are the two key factors to calculate all the costs. The required service frequency function is defined as

$$
F=\frac{\alpha \times \mathrm{PAX}}{\text { VehCap } \times \text { MaxLF }}
$$

where $\alpha$ is a factor to allow for seasonal fluctuations, for which the default value is $1 \cdot 1$ and can be modified by the user, PAX is the demand for the time period, VehCap is the vehicle capacity (including seating and standing space) and MaxLF is the maximum relative load factor at which level a new vehicle is required, which is set to $50 \%$ as default. The required service frequency $F$ is associated with the average operational speed $V^{\mathrm{ALL}}$, which is calculated as

$$
V^{\mathrm{ALL}}=V^{\mathrm{NoCap}}\left(1-\frac{F}{C}\right)
$$

in which $V^{\mathrm{NoCap}}$ is the vehicle operational speed calculated by using the default (or user defined) value of acceleration, maximum speed, station spacing, stopping time and passenger boarding/ alighting time without considering the capacity of the infrastructure, and the variable $C$ is the infrastructure capacity, which is the maximum possible vehicle numbers per lane (for road-based systems) or per track (for rail-based systems). With the restraint of the infrastructure capacity, the average operational speed can then reflect the traffic situation when the congestion of the system due to passenger demand rises. The infrastructure capacity can be defined by users for the technologies that allow overtaking or calculated by the following equations for technologies where overtaking is not possible.

$$
\begin{aligned}
& C=\frac{3600}{H} \\
& H=T^{\mathrm{Veh}}+\left(\frac{2 L^{\mathrm{Veh}}}{A}\right)^{1 / 2}+\frac{L^{\mathrm{Veh}}}{V^{\mathrm{Max}}}+\frac{V^{\mathrm{Max}}}{2 A}
\end{aligned}
$$

where $H$ is the safety headway (in seconds) to calculate the minimum possible service interval without any passenger boarding, $T^{\mathrm{Veh}}$ is the vehicle stopping time, which includes opening/ closing doors and changing shifts for drivers, $L^{\mathrm{Veh}}$ is the length of the vehicle, $V^{\mathrm{Max}}$ is the maximum possible running speed and $A$ is the acceleration and deceleration of the vehicle. Alternative speed flow relationships based on piecewise linear or power laws can be used where local data exist (e.g. Small, 1992: pp. 71-72).

These two parameters are closely associated with the calculation of total cost. For example, the peak vehicle requirement can be assessed after determining the service frequency and then the capital investment for buying vehicles can be obtained; the waiting time and in-vehicle time for passengers are highly related to the service frequency and the average operational speed of the public transport service. With the calculation of the service frequency $F$ and the average operational speed $V^{\mathrm{ALL}}$, the TEST spreadsheet model is able to compare the average social cost and marginal social cost of 15 public transport technologies, where the average social cost is calculated as total social cost divided by passenger kilometres (TSC/pkm) and the marginal social cost is $\partial \mathrm{TSC} / \partial \mathrm{pkm}$.

\subsection{Straddle bus}

The straddle bus, as a typical innovative transport technology, was added in this study in order to further complete this assessment method. Because the prototype is still under construction, the basic data (i.e. vehicle length, capacities and speeds) used are according to the promotional video (Sadieblooming, 2010) and the unit costs are assumed based on other similar technologies. Other public transport technologies that could be added include the next-generation transport trolley bus scheme proposed for Leeds (NGT, 2014). All of the public transport technologies modelled in this study are shown in Table 2. Note that the maximum capacity of the straddle bus is assumed to be $166 \%$ of modern light rail as the four-car unit straddle bus has a greater length and, occupying two lanes rather than one, also greater width.

In order to update the model, the cost data for each public transport technology were increased according to the retail price index (RPI) level difference between 2011 and 2000. Based on RPI reference tables published by the UK Office for National Statistics (ONS, 2011), the RPI value in January 2000 was $166 \cdot 6$ and 229.0 in January 2011 (January 1987 RPI $=100$ ). Therefore, the price increment factor that should be applied to the new cost data is $229 \cdot 0 / 166 \cdot 6=1 \cdot 37$; the cost tables that sum up all the public transport technologies in this study are based on the 


\begin{tabular}{|c|c|c|c|}
\hline Category Technology & Description & $\begin{array}{l}\text { Maximum } \\
\text { number of } \\
\text { passengers }\end{array}$ & $\begin{array}{c}\text { Maximum } \\
\text { speed: } \\
\text { km/h }\end{array}$ \\
\hline \multicolumn{4}{|l|}{ Small vehicle technology } \\
\hline Minibus & Minibus (e.g. Ford Transit, Mercedes Sprinter) & 16 & 50 \\
\hline PRT & $\begin{array}{l}\text { ULTra system as proposed for Cardiff and completed at } \\
\text { Heathrow airport }\end{array}$ & 4 & 40 \\
\hline \multicolumn{4}{|l|}{ Conventional bus technology } \\
\hline Single bus & Low-floor single-decker bus in mixed traffic & 75 & 50 \\
\hline Articulated bus & Low-floor articulated bus in mixed traffic & 90 & 50 \\
\hline Double bus & Low-floor double-decker bus in mixed traffic & 85 & 50 \\
\hline Single bus on bus lane & Low-floor single-decker bus on (non-segregated) bus lanes & 75 & 50 \\
\hline Single bus on busway & Low-floor single-decker bus on segregated busway & 75 & 50 \\
\hline Single bus on guideway & Low-floor single-decker bus on guided busway & 75 & 50 \\
\hline Double bus on guideway & Low-floor double-decker bus on guided busway & 85 & 50 \\
\hline \multicolumn{4}{|l|}{ Light rail transit } \\
\hline GLT & Tram-on-tyres type vehicle (e.g. Caen GLT) & 125 & 50 \\
\hline Straddle bus & Assumed four-car unit straddle bus that occupies two lanes & 367 & 60 \\
\hline Modern light rail & Typical three-car unit LRV for urban services (e.g. Croydon, UK) & 220 & 60 \\
\hline LRV tracksharing & $\begin{array}{l}\text { Typical three-car unit LRV for inter-urban services (e.g. Karlsruhe, } \\
\text { Germany) }\end{array}$ & 220 & 60 \\
\hline \multicolumn{4}{|l|}{ Heavy rail transit } \\
\hline Suburban heavy rail & Two-unit inter-urban heavy rail on segregated tracks & 250 & 112 \\
\hline Regional heavy rail & Four-unit inter-urban heavy rail on segregated tracks & 400 & 160 \\
\hline Underground & $\begin{array}{l}\text { Typical urban metro in large city (e.g. London underground) } \\
\text { (assume six-car unit) }\end{array}$ & 500 & 40 \\
\hline
\end{tabular}

Table 2. Description of the public transport technologies

modelled

original cost tables of Brand and Preston (2003a: Tables 2-6). The recalculated unit operating costs are shown in Table 3.

For the straddle bus, all of the default unit costs are assumed to be the same as modern light rail. This is because the operation of the straddle bus is similar to modern light rail (e.g. Manchester Metrolink), which can also operate on the existing road surface with steel-wheel (Knowles, 2007) rather than the guided light transit (GLT) with rubber tyre, and the insurance and maintenance of this innovative technology should be much higher than conventional buses. The total vehicle-related cost for the straddle bus is $1 / 3$ higher because it has more car units for one vehicle than modern light rail.

A sensitivity test was performed to investigate the differences if the default costs were developed using other light rail transit systems (e.g. GLT and light rail vehicle (LRV) tracksharing). From the sensitivity test, the average operator costs range from $-24 \%$ for GLT to $+10 \%$ for LRV tracksharing and the average social costs from $-7 \cdot 5 \%$ for GLT to $+1 \cdot 9 \%$ for LRV tracksharing. The differences were not notable except for the operator costs using GLT unit costs, but the most feasible demand range for the straddle bus stayed unchanged. Therefore, the default unit costs were assumed based on modern light rail technology. The main characteristics of the public transport technologies modelled are given in Table 4.

The capacity of the straddle bus is assumed to be 367 , which is $166 \%$ greater than the modern light rail to account for the extra length and width while providing more seats, and the vehicle length of a 4-car unit is $40 \mathrm{~m}$ according to the presentation of the inventor Youzhou Song (Sadieblooming, 2010). The infrastructure capacity is related to the acceleration, vehicle speed and the vehicle length as explained in Section 2.1. The default capital investments of infrastructure and vehicle are shown in Table 5.

As the infrastructure of the straddle bus requires only road reconstruction and new stations, the cost is believed be 50 million $\mathrm{RMB} / \mathrm{km}$ (Sadieblooming, 2010) while underground costs in China are about 500 million $\mathrm{RMB} / \mathrm{km}$. Considering price differences between the UK and China (including labour costs and material costs), the Organisation for Economic Co-operation and Development (OECD) purchasing power parity (PPP) rate is used. The PPP rate is an economic theory construct to consider the value of currencies, which considers both the currency rates and the purchasing power of different countries (OECD, 2011). 


\begin{tabular}{|c|c|c|c|c|c|}
\hline Category & Technology & $\begin{array}{l}\text { Time-related } \\
\text { costs: } \\
\text { f/vehicle hour }\end{array}$ & $\begin{array}{l}\text { Distance-related } \\
\text { costs: } \\
\text { f/vehicle km }\end{array}$ & $\begin{array}{l}\text { Route maintenance- } \\
\text { related costs: } \\
\text { f/route km per year }\end{array}$ & $\begin{array}{l}\text { Vehicle-related } \\
\text { f/peak vehic } \\
\text { requirement pe }\end{array}$ \\
\hline \multicolumn{6}{|c|}{ Small vehicle technology } \\
\hline & Minibus & $10 \cdot 600$ & $0 \cdot 139$ & 2642 & 4292 \\
\hline & PRT & $1 \cdot 325$ & $0 \cdot 139$ & 2642 & 661 \\
\hline \multicolumn{6}{|c|}{ Conventional bus technology } \\
\hline & Single bus & $13 \cdot 250$ & $0 \cdot 277$ & 2642 & 17168 \\
\hline & Articulated bus & $13 \cdot 913$ & $0 \cdot 305$ & 2642 & 18885 \\
\hline & Double bus & $13 \cdot 913$ & $0 \cdot 333$ & 2642 & 20601 \\
\hline & Single bus on bus lane & $13 \cdot 250$ & $0 \cdot 264$ & 3963 & 17168 \\
\hline & Single bus on busway & $13 \cdot 250$ & $0 \cdot 264$ & 3963 & 17168 \\
\hline & Single bus on guideway & $13 \cdot 581$ & $0 \cdot 277$ & 6605 & 18026 \\
\hline & Double bus on guideway & $13 \cdot 581$ & $0 \cdot 277$ & 6605 & 18026 \\
\hline \multicolumn{6}{|c|}{ Light rail transit } \\
\hline & GLT & $13 \cdot 581$ & 0.366 & 6605 & 22318 \\
\hline & Straddle bus & $62 \cdot 219$ & 0.661 & 12880 & 61835 \\
\hline & Modern light rail & $62 \cdot 219$ & 0.661 & 12880 & 46376 \\
\hline & LRV tracksharing & $62 \cdot 219$ & 0.661 & 10806 & 90116 \\
\hline \multicolumn{6}{|c|}{ Heavy rail transit } \\
\hline & Suburban heavy rail & $54 \cdot 954$ & 1.057 & 19815 & 66050 \\
\hline & Regional heavy rail & $123 \cdot 910$ & $2 \cdot 153$ & 60269 & 292872 \\
\hline & Underground & $84 \cdot 676$ & $4 \cdot 597$ & 541512 & 106787 \\
\hline
\end{tabular}

Table 3. Default unit costs (2011 prices)

According to PPP rates in 2011, the PPP for the UK is 0.679 (USA PPP $=1.000$ ) while China is 4.173 and therefore a factor of $0 \cdot 163(=0 \cdot 679 / 4 \cdot 173)$ was used. The default infrastructure cost of the straddle bus, including reconstruction of roads and stations/stops, was hence assumed to be $£ 8.15$ million $/ \mathrm{km}$.

The vehicle cost for the straddle bus is still unknown as the prototype is still under construction and the feasibility report is not yet available to the public. Therefore, due to its high-tech requirements, the default vehicle cost is assumed to be $50 \%$ higher than modern light rail to account for the extra capacity; the economic life expected for both vehicle and infrastructure are assumed to be the same as they are both modes of rail transport operating on existing roads.

The default external costs for each public transport technology are shown in Table 6. The straddle bus has an electric motor design similar to the technology of overhead chargers in each terminal station adopted by trolley buses. As a result, the costs for the straddle bus are assumed to be as low as modern light rail.

\subsection{Operating the spreadsheet model}

The spreadsheet model, based on Microsoft Excel, is able to simulate the operation of public transport over a $12-\mathrm{km}$ route for different passenger demand levels (assuming demand level from 1000 to $200000 \mathrm{ppd}$ ) and to obtain social costs during the operation. The basic equation for the cost calculation has been explained earlier, and these costs are determined in terms of the unit costs and vehicle data (default or user input) as well as the intermediate outputs such as average operational speed, service frequency required to meet demand, vehicle kilometres (vkm), passenger kilometres (pkm), vehicle hours, peak vehicle requirements and so on. All of the detailed equations and internal variable values can be found in the work by Brand and Preston (2003a).

The logical running procedure of the spreadsheet model is shown in Figure 1. After the iteration process for different demand levels and the 16 public transport technologies, the total operator costs and total social costs can then be aggregated in one chart to produce the final result graph. Among the input data, the demand level starts from $1000 \mathrm{ppd}$ to $200000 \mathrm{ppd}$ in the iteration, and the values that users are required to input include weekdays per year and average passenger journey length. The default values in the model can be modified by the user to update the data according to other updated values or to create another analysis sector for a new public transport technology. The default parameters in the spreadsheet model include

- infrastructure capacity - the maximum vehicle number in the corridor per hour

- vehicle capacity - the maximum allowable passenger number (seating and standing) for each vehicle 


\begin{tabular}{|c|c|c|c|c|c|c|c|}
\hline \multirow[t]{2}{*}{ Category } & \multirow[t]{2}{*}{ Technology } & \multicolumn{2}{|c|}{ Vehicle capacity } & \multirow[t]{2}{*}{$\begin{array}{l}\text { Vehicle length: } \\
\text { m }\end{array}$} & \multicolumn{2}{|c|}{$\begin{array}{l}\text { Maximum allowable vehicle } \\
\text { speed: } \mathrm{km} / \mathrm{h}\end{array}$} & \multirow{2}{*}{$\begin{array}{c}\text { Infrastructure } \\
\text { capacity: } \\
\text { vehicles/h }\end{array}$} \\
\hline & & Seats only & Total & & Urban & Inter-urban & \\
\hline \multicolumn{8}{|c|}{ Small vehicle technology } \\
\hline & Minibus & 16 & 16 & $7 \cdot 0$ & 50 & 80 & 400 \\
\hline & PRT & 4 & 4 & $3 \cdot 5$ & 40 & 40 & 1800 \\
\hline \multicolumn{8}{|c|}{ Conventional bus technology } \\
\hline & Single bus & 40 & 75 & $12 \cdot 0$ & 50 & 80 & 250 \\
\hline & Articulated bus & 60 & 90 & $18 \cdot 0$ & 50 & 80 & 167 \\
\hline & Double bus & 78 & 85 & $12 \cdot 0$ & 50 & 80 & 250 \\
\hline & Single bus on bus lane & 40 & 75 & $12 \cdot 0$ & 50 & 80 & 250 \\
\hline & Single bus on busway & 40 & 75 & $12 \cdot 0$ & 50 & 80 & 250 \\
\hline & Single bus on guideway & 40 & 75 & $12 \cdot 0$ & 50 & 80 & 133 \\
\hline & Double bus on guideway & 78 & 85 & $12 \cdot 0$ & 50 & 80 & 133 \\
\hline \multicolumn{8}{|c|}{ Light rail transit } \\
\hline & GLT & 75 & 125 & $24 \cdot 5$ & 50 & 80 & 121 \\
\hline & Straddle bus & 167 & 367 & $40 \cdot 0$ & 60 & 60 & 113 \\
\hline & Modern light rail & 100 & 220 & $30 \cdot 0$ & 60 & 100 & 139 \\
\hline & LRV tracksharing & 100 & 220 & $30 \cdot 0$ & 60 & 100 & 139 \\
\hline \multicolumn{8}{|c|}{ Heavy rail transit } \\
\hline & Suburban heavy rail & 150 & 250 & $50 \cdot 0$ & N/A & 112 & 104 \\
\hline & Regional heavy rail & 220 & 400 & $64 \cdot 0$ & N/A & 160 & 76 \\
\hline & Underground & 240 & 500 & $72 \cdot 0$ & 40 & N/A & 125 \\
\hline
\end{tabular}

maximum speed - the maximum vehicle travel speed in free flow conditions

vehicle length - the vehicle length (in total if the vehicle is more than one car unit)

- supply/demand factor - to take seasonal changes into account

- maximum load factor - the maximum relative load factor to require a new vehicle

- acceleration and deceleration - the acceleration and deceleration rate for the vehicle

- stop distance - the average distance between stops for public transport $(0.4 \mathrm{~km}$ for conventional buses, $1 \mathrm{~km}$ for urban rail technologies and $10 \mathrm{~km}$ for inter-urban heavy rail technologies as default values)

- stop time - the average vehicle stopping time at each stop

- passenger boarding time - the average boarding time per passenger

- track length - the total corridor length for a single direction (12 km for this study)

- unit operator costs - the default unit time-, distance-, vehicleand route maintenance-related costs as indicated in Table 3

- economic life - the expected useful life for a vehicle and the infrastructure

- unit capital investment - capital costs for a vehicle and the whole infrastructure, as indicated in Table 5

- unit external costs - the costs of air pollution, noise pollution, climate change and external accidents per vehicle kilometre as indicated in Table 6.

Note that the default values used are from the work of Brand and Preston (2001), which includes detailed reviews of the characteristics of different public transport technologies. Therefore, the developed model can be further updated using the most up-todate parameter values and hence give a clear comparative view for different public transport modes operating on a route.

\section{Demand-supply relationship}

In the spreadsheet model, in order to analyse the transportation cost for different public transport technologies, passenger demand and vehicle supply are considered as important factors. Costs and benefits would vary for each technology when the passenger demand level rises from 1000 ppd to 200000 ppd step by step in the model. More vehicles would be needed for increasing passenger numbers and this affects the total social costs for the extra vehicle numbers.

Daily passenger demand level in the model is changed in the calculation procedure for every 1000 passengers, which means that demand is assumed to be exogenous - externally fixed by the spreadsheet model. In this way, the model can easily gather the total cost data for each demand level by using macro scripts in 


\begin{tabular}{|c|c|c|c|c|}
\hline \multirow[t]{2}{*}{ Category } & \multirow[t]{2}{*}{ Technology } & \multirow{2}{*}{$\begin{array}{l}\text { Infrastructure costs: } \\
\text { fmillion/km }\end{array}$} & \multirow{2}{*}{$\begin{array}{l}\text { Vehicle costs: } \\
\text { f/vehicle }\end{array}$} & Economic life: years \\
\hline & & & & Infrastructure \\
\hline
\end{tabular}

Small vehicle technology

Minibus

PRT

0.66

Light rail transit

Single bus on guideway

Double bus on guideway

\section{GLT}

Straddle bus

Modern light rail

LRV tracksharing

Heavy rail transit

$$
\begin{aligned}
& \text { Suburban heavy rail } \\
& \text { Regional heavy rail } \\
& \text { Underground }
\end{aligned}
$$

$3 \cdot 05$

0.66

0.66

$0 \cdot 66$

$1 \cdot 31$

$6 \cdot 61$

$4 \cdot 80$

$4 \cdot 80$

79260

33025

145310

198150

198150

145310

145310

151915

204755

$3 \cdot 30$

$8 \cdot 15$

$9 \cdot 15$

$5 \cdot 30$

$13 \cdot 21$

$26 \cdot 42$

$105 \cdot 68$
1453100

2774100

1849400

1981500

2377800

3302500

2642000
25

25

25

25

25

25

25

25

25

25

25

25

50

50

50

50

Table 5. Default unit capital costs and economic life expectancies

Microsoft Excel of entering each demand level and then obtaining the corresponding operator costs, user costs and external costs for the selected public transport technology. However, the supply requirement calculation model has to assume the level of passenger demand as externally fixed in the first place, so the calculation cannot reflect the situation that passengers' willingness to use the service varies according to the quality of service. The total operator costs could be the same, but not the total user costs and the average costs. As a result of that, further analysis of the demand-supply relationship must be conducted to obtain the actual average costs. In reality, the endogenous passenger demand is closely related to the performance of the technology, as are user benefits such as service frequency, passenger waiting time and in-vehicle time for the whole journey. Those factors would have a great impact on passengers' willingness to use the public transport as well as their travel behaviours. For example, passengers tend to prefer the public transport technology that has the higher service frequency and therefore less waiting time cost for them at a station. For public transport services with high frequency, passenger waiting time at a station is normally equal to half of the service headway because passengers arrive at the station/stop independently of the service schedule if the service frequency is high enough: this passenger behaviour will change and a specific departure will be timed in order to reduce waiting time at the station when the service headway is much wider (typically the threshold is a headway of 12-15 min) (Balcombe et al., 2004).

\subsection{Elasticity}

In order to investigate the internal impact of users' waiting time and in-vehicle time on the current demand level, the concept of demand elasticity is introduced. Elasticity is frequently used to measure how sensitive a factor is to changes in another factor: demand elasticity means the demand level is one of the changing factors. In the spreadsheet model, the attractiveness of a public transport technology is significantly enhanced when the service interval is shorter, and the demand elasticity factor can show how much the demand level will grow in response to a decrease in service headway. The elasticity of demand can be defined as

$$
\begin{aligned}
E_{x} & =\frac{\text { Proportional change in demand }}{\text { Proportional change in the variable of interest }} \\
& =\frac{\Delta Q / Q}{\Delta x / x}
\end{aligned}
$$

where $Q$ is the demand, $\Delta Q$ is the change in demand and $\Delta x$ is the change in the variable $x$ that we are interested in (e.g. service headway). In this definition, $x$ can be any factor that would affect demand level.

Time is one of the most important factors impacting on the service quality of public transport; it is made up of three main elements - access/egress time, waiting time and journey time. 


\begin{tabular}{|c|c|c|c|c|c|c|c|c|c|c|c|c|}
\hline \multirow{2}{*}{$\begin{array}{l}\text { Technology } \\
\text { Minibus }\end{array}$} & \multicolumn{3}{|c|}{$\begin{array}{l}\text { Air pollution: } \\
\text { p/vkm }\end{array}$} & \multicolumn{3}{|c|}{$\begin{array}{c}\text { Noise pollution: } \\
\text { p/vkm }\end{array}$} & \multicolumn{3}{|c|}{$\begin{array}{c}\text { Climate change: } \\
\text { p/vkm }\end{array}$} & \multicolumn{3}{|c|}{ Accidents/vkm } \\
\hline & $8.7^{d}$ & $16 \cdot 5^{d}$ & $25 \cdot 2^{d}$ & $1 \cdot 3^{d}$ & $5 \cdot 8^{d}$ & $6 \cdot 9^{d}$ & $1 \cdot 2^{d}$ & $1 \cdot 5^{d}$ & $1.7^{d}$ & $0 \cdot 3$ & $1 \cdot 7$ & $3 \cdot 2$ \\
\hline PRT & $0.7^{\mathrm{e}}$ & $1 \cdot 3^{e}$ & $2 \cdot 4^{\mathrm{e}}$ & $0.5^{e}$ & $1 \cdot 1^{\mathrm{e}}$ & $1.7 \mathrm{e}$ & $0.4^{e}$ & $0.8^{e}$ & $1 \cdot 5^{\mathrm{e}}$ & - & $0 \cdot 1$ & - \\
\hline Single bus & $14 \cdot 5$ & $27 \cdot 6$ & $42 \cdot 1$ & $2 \cdot 8$ & $11 \cdot 8$ & $13 \cdot 9$ & $2 \cdot 1$ & $2 \cdot 4$ & $2 \cdot 8$ & $0 \cdot 3$ & $1 \cdot 7$ & $3 \cdot 2$ \\
\hline Articulated bus & $17 \cdot 4^{a}$ & $33 \cdot 2^{a}$ & $50 \cdot 6^{a}$ & $2 \cdot 8$ & $11 \cdot 8$ & $13 \cdot 9$ & $2 \cdot 5$ & $2 \cdot 9$ & $3 \cdot 3$ & $0 \cdot 3$ & $1 \cdot 7$ & $3 \cdot 2$ \\
\hline Double bus & $16 \cdot 0^{b}$ & $30 \cdot 4^{b}$ & $46 \cdot 4^{b}$ & $2 \cdot 8$ & $11 \cdot 8$ & $13 \cdot 9$ & $2 \cdot 2$ & $2 \cdot 6$ & $3 \cdot 0$ & $0 \cdot 3$ & $1 \cdot 7$ & $3 \cdot 2$ \\
\hline Single bus on bus lane & $14 \cdot 5$ & $27 \cdot 6$ & $42 \cdot 1$ & $2 \cdot 8$ & $11 \cdot 8$ & $13 \cdot 9$ & $1 \cdot 8^{g}$ & $2 \cdot 1^{\mathrm{g}}$ & $2 \cdot 5^{g}$ & $0 \cdot 3$ & $1 \cdot 7$ & $3 \cdot 2$ \\
\hline Single bus on busway & $14 \cdot 5$ & $27 \cdot 6$ & $42 \cdot 1$ & $2 \cdot 8$ & $11 \cdot 8$ & $13 \cdot 9$ & $1.8^{9}$ & $2 \cdot 1 \mathrm{~g}$ & $2 \cdot 5^{g}$ & 0.3 & $1 \cdot 7$ & $3 \cdot 2$ \\
\hline Single bus on guideway & $14 \cdot 5$ & $27 \cdot 6$ & $42 \cdot 1$ & $2 \cdot 8$ & $11 \cdot 8$ & $13 \cdot 9$ & $1.8^{9}$ & $2 \cdot 1 \mathrm{~g}$ & $2 \cdot 5^{g}$ & $0 \cdot 3$ & $1 \cdot 7$ & $3 \cdot 2$ \\
\hline Double bus on guideway & $16 \cdot 0^{b}$ & $30 \cdot 4^{b}$ & $46 \cdot 4^{b}$ & $2 \cdot 8$ & $11 \cdot 8$ & $13 \cdot 9$ & $2 \cdot 1^{\mathrm{h}}$ & $2 \cdot 4^{h}$ & $2 \cdot 8^{h}$ & $0 \cdot 3$ & $1 \cdot 7$ & $3 \cdot 2$ \\
\hline GLT & $7 \cdot 3^{c}$ & $13 \cdot 9^{c}$ & $21 \cdot 0^{c}$ & $1 \cdot 8^{f}$ & $7 \cdot 8^{f}$ & $9 \cdot 2^{f}$ & $2 \cdot 1^{c}$ & $2 \cdot 4^{c}$ & $2 \cdot 8^{c}$ & $0 \cdot 3$ & $1 \cdot 7$ & $3 \cdot 2$ \\
\hline Straddle bus & $7 \cdot 1$ & $13 \cdot 3$ & $21 \cdot 0$ & $10 \cdot 0$ & $21 \cdot 8$ & $33 \cdot 6$ & $3 \cdot 7$ & $7 \cdot 5$ & $14 \cdot 9$ & - & 0.0 & - \\
\hline Modern light rail & $7 \cdot 1$ & $13 \cdot 3$ & $23 \cdot 6$ & $10 \cdot 0$ & $21 \cdot 8$ & $33 \cdot 6$ & $3 \cdot 7$ & $7 \cdot 5$ & $14 \cdot 9$ & - & 0.0 & - \\
\hline LRV tracksharing & $7 \cdot 1$ & $13 \cdot 3$ & $23 \cdot 6$ & $10 \cdot 0$ & $21 \cdot 8$ & $33 \cdot 6$ & $3 \cdot 7$ & $7 \cdot 5$ & $14 \cdot 9$ & - & 0.0 & - \\
\hline Suburban heavy rail & $4 \cdot 5$ & $12 \cdot 3$ & $23 \cdot 2$ & $12 \cdot 2$ & $26 \cdot 2$ & $40 \cdot 2$ & $4 \cdot 2$ & $8 \cdot 6$ & $17 \cdot 0$ & - & 0.0 & - \\
\hline Regional heavy rail & $5 \cdot 5$ & $14 \cdot 0$ & $25 \cdot 8$ & $4 \cdot 9$ & $10 \cdot 6$ & $16 \cdot 2$ & $4 \cdot 5$ & $8 \cdot 9$ & $17 \cdot 7$ & - & 0.0 & - \\
\hline Underground & - & $24 \cdot 8$ & - & - & $26 \cdot 3$ & - & - & $8 \cdot 3$ & - & - & 0.0 & - \\
\hline
\end{tabular}

${ }^{a}$ Assumed 20\% higher local air pollution emissions (mainly PM10) than single bus, mainly due to higher weight and larger engines.

${ }^{\mathrm{b}}$ Assumed 10\% higher local air pollution emissions (mainly PM10) than single bus, mainly due to higher weight and larger engines.

c Assumed $50 \%$ lower local air pollution emissions than single bus, mainly due to hybrid-electric propulsion; climate change impacts similar to articulated bus.

${ }^{d}$ Assumed $40 \%$ lower local air pollution and climate change emissions than single bus, mainly due to smaller engines and lower weight.

${ }^{\text {e }}$ Assumed to be $10 \%$ of light rail costs.

${ }^{\dagger}$ Assumed $33 \%$ lower noise emissions than single bus, mainly due to quieter hybrid-electric propulsion.

${ }^{9}$ Assumed $10 \%$ lower carbon dioxide emissions per kilometre than single bus due to less congested running and therefore better fuel consumption.

${ }^{\mathrm{h}}$ Assumed $10 \%$ higher carbon dioxide emissions per kilometre than single bus due to increased weight and engine size but less congested running and therefore better fuel consumption.

Table 6. Default external unit costs by impact category (Sansom et al. (2001); low-noise values for bus-based technologies based on Euro 1 14-15 t two-axle HGV (Ricci and Friedrich, 1999; NERA, AEA Technology Environment and TRL, 1999))

Passenger access/egress time is calculated as the time spent walking to/from the station/stop. In the model, the space between stations/stops can be set by the user or the default value can be used, and the mean walking distance is a quarter of this spacing (Nash, 1988). In practice, for rail systems, some passengers will access/egress using mechanised modes. This factor is not changed with the level of demand and therefore the variables of interest in the elasticity equation are the service frequency of the public transport technology and the average time spent in the vehicle for each passenger in this analysis. Those elasticities vary for different transport types, city sizes, vehicle kilometres and also journey purpose (e.g. working or shopping). Demand elasticities of service frequency and passenger in-vehicle time have been developed in many previous studies.
Service frequency is closely related to the waiting time of passengers. The demand elasticity of passenger waiting time was estimated by Preston and James (2000) based on an analysis of bus data in 23 urban areas in Great Britain. Waiting time elasticities for UK cities analysis were reported by Balcombe et al. (2004) and the average elasticity was calculated as $-0 \cdot 64$ : this means that every $1 \%$ of increasing or decreasing wait time will have an effect of a $0.64 \%$ decrease or increase in demand level. The waiting time elasticity value of -0.64 is used in this analysis.

For the elasticity of passenger in-vehicle time, less journey time is always preferred. So, for any increment in the time spent on board, passenger demand level will fall, which means that journey 


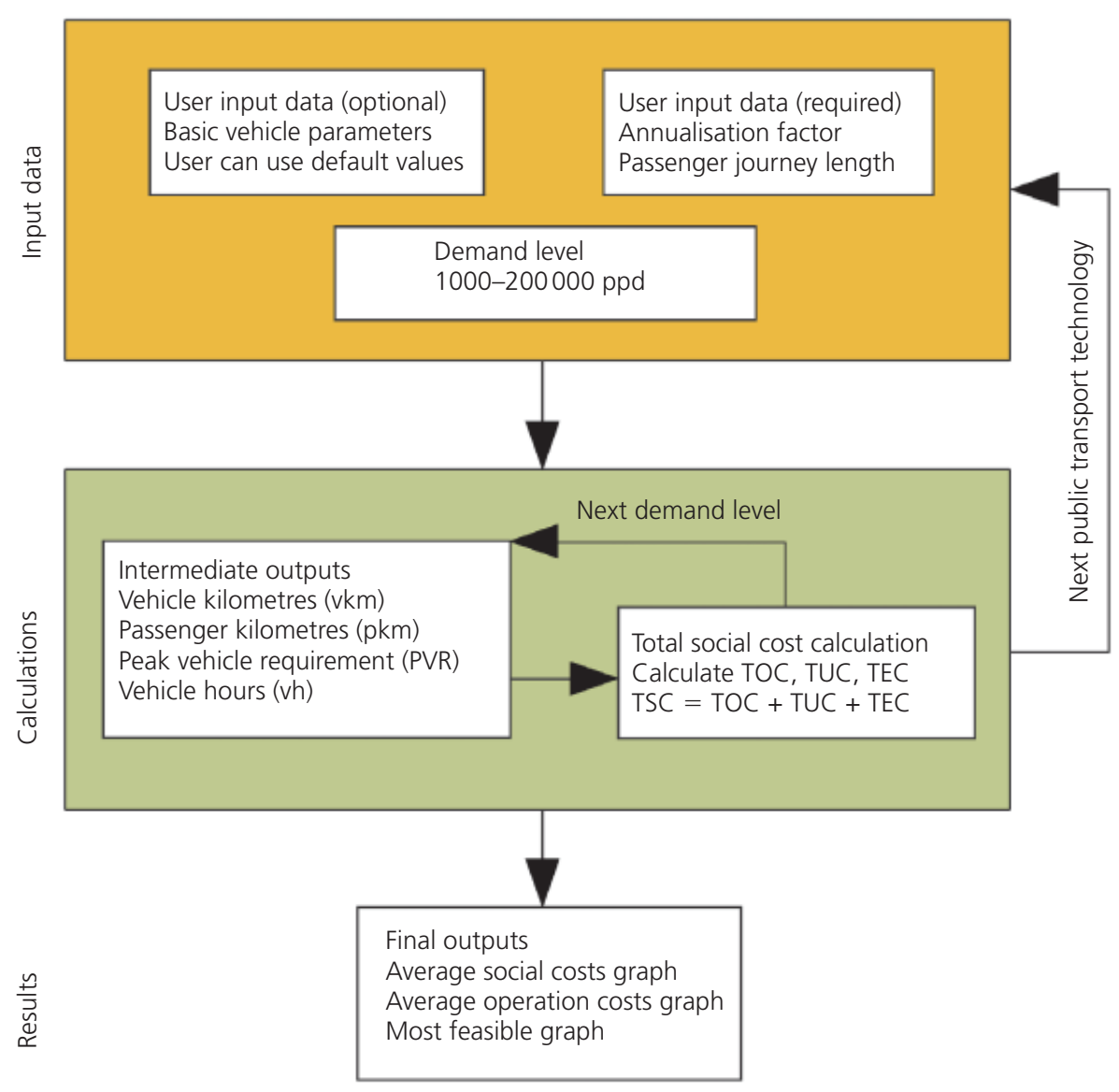

Figure 1. Operation procedure of the spreadsheet model

time elasticity is always negative. Review studies have been done all around the world for different cities. The in-vehicle time elasticity for buses was estimated to be approximately -0.4 by Daugherty et al. (1999) after reviewing bus priority schemes in Great Britain. For rail transit, journey time elasticities are more sensitive than those for conventional buses. The average journey time elasticities for rail technologies are from -0.6 to -0.8 in the UK (SDG, 1999), which means railway passengers are up to twice as sensitive as people using bus transit if the in-vehicle time varies. So, in the spreadsheet model, the in-vehicle elasticity for buses would be $-0 \cdot 4$, an elasticity value of $-0 \cdot 6$ would be adopted for light rail transit and $-0 \cdot 8$ for heavy rail transit.

\subsection{Model calculation}

Based on the elasticity definition and the value of service elasticity and in-vehicle time elasticity of demand, the original model can be modified to compare the difference between exogenous demand and endogenous demand affected by the elasticity. The calculation of the spreadsheet model will compute the total social costs of all the public transport technologies listed in the model, as well as all the intermediate outputs during the calculation. From those intermediate outputs, service frequency and journey time per passenger every hour would be extracted to calculate the actual demand by using the elasticity model.

The demand elasticity model uses the constant elasticity model of demand as

$$
\begin{aligned}
Q_{1} & =Q_{0}\left(\frac{T_{1}^{\text {wait }}}{T_{0}^{\text {wait }}}\right)^{E_{1}}\left(\frac{\mathrm{JT}_{1}}{\mathrm{JT}_{0}}\right)^{E_{2}} \\
T^{\text {wait }} & =T^{\text {stop }}+\frac{H}{2}
\end{aligned}
$$

where $Q_{1}$ is the endogenous demand level, $Q_{0}$ is the input exogenous demand level from $1000 \mathrm{ppd}$ to $200000 \mathrm{ppd}, T_{1}^{\text {wait }}$ is the passenger waiting time at an exogenous demand level of the public transport mode, $T_{0}^{\text {wait }}$ is the average passenger waiting time frequency at a fixed demand level for all modes $(=10000$ passenger trips per day), $\mathrm{JT}_{1}$ is the journey time at an exogenous demand level of the public transport mode, $\mathrm{JT}_{0}$ is the average journey time at a fixed demand level for all modes $(=10000$ passenger trips per day), $E_{1}$ is the demand waiting time elasticity, 
Reassessing the financial and social costs

of public transport

Li and Preston
$E_{2}$ is the demand journey time elasticity, $T^{\text {stop }}$ is the vehicle stopping time per stop including passengers boarding and alighting and $H$ is the service headway at a fixed demand level.

This equation uses elasticities of waiting time and journey time to calculate the difference between the fixed demand level and the endogenous demand level when the public transport technologies are operating on road. By applying this equation to the spreadsheet model for every step of the exogenous demand from $1000 \mathrm{ppd}$ to $200000 \mathrm{ppd}$, the original average demand level would change due to the elasticity factor, and then the graph of endogenous demand against the original exogenous demand can be produced.

\subsection{Endogenous demand and exogenous demand relationship}

From the calculation procedure in the previous section, actual passenger demand is affected by the supply level of the vehicles, mostly the interval between services and the efficiency of the whole travel (journey time). The raw output graph produced in Microsoft Excel is shown in Figure 2.

The $x$-axis of the graph shows the demand level when it is externally fixed and the $y$-axis shows the demand level when the influences of supply on demand are introduced into the model. The endogenous demand levels are shown as a percentage of the current exogenous demand level to demonstrate the relationship between them.
From Figure 2, exogenous demand might be thought of as demand that is fixed at specified headways and journey times. At low demand levels, personal rapid transit (PRT) stands out because of its higher frequency (due to small vehicles) and faster speeds (due to segregated rights of way and low stopping time) and, in this case, endogenous demand is greater than exogenous demand. At high exogenous demand levels, endogenous demand is less than exogenous levels because this high passenger demand level would cause traffic congestion, which would lower the operating speed and eventually make the in-vehicle time higher. Passengers' waiting time would also be affected as vehicles have to spend more time at stations/stops for boarding/alighting passengers.

Figure 2 also demonstrates the attractiveness of these 16 public transport technologies in different demand levels. For example, the double-decker bus technology has a higher percentage of fixed passenger demand than other transport modes in the demand level from 35000 ppd to $75000 \mathrm{ppd}$. PRT and minibus technologies have a very high endogenous demand level compared with other public transport modes, especially before the exogenous demand reaches $27000 \mathrm{ppd}$. This is because the service intervals are much lower than other technologies and they are thus much more attractive for passengers that value their waiting time more highly. The endogenous demand growth of underground is quite stable and shows its advantages, especially at high exogenous demand levels. The reason for this is that the service interval of underground is very high with a low passenger

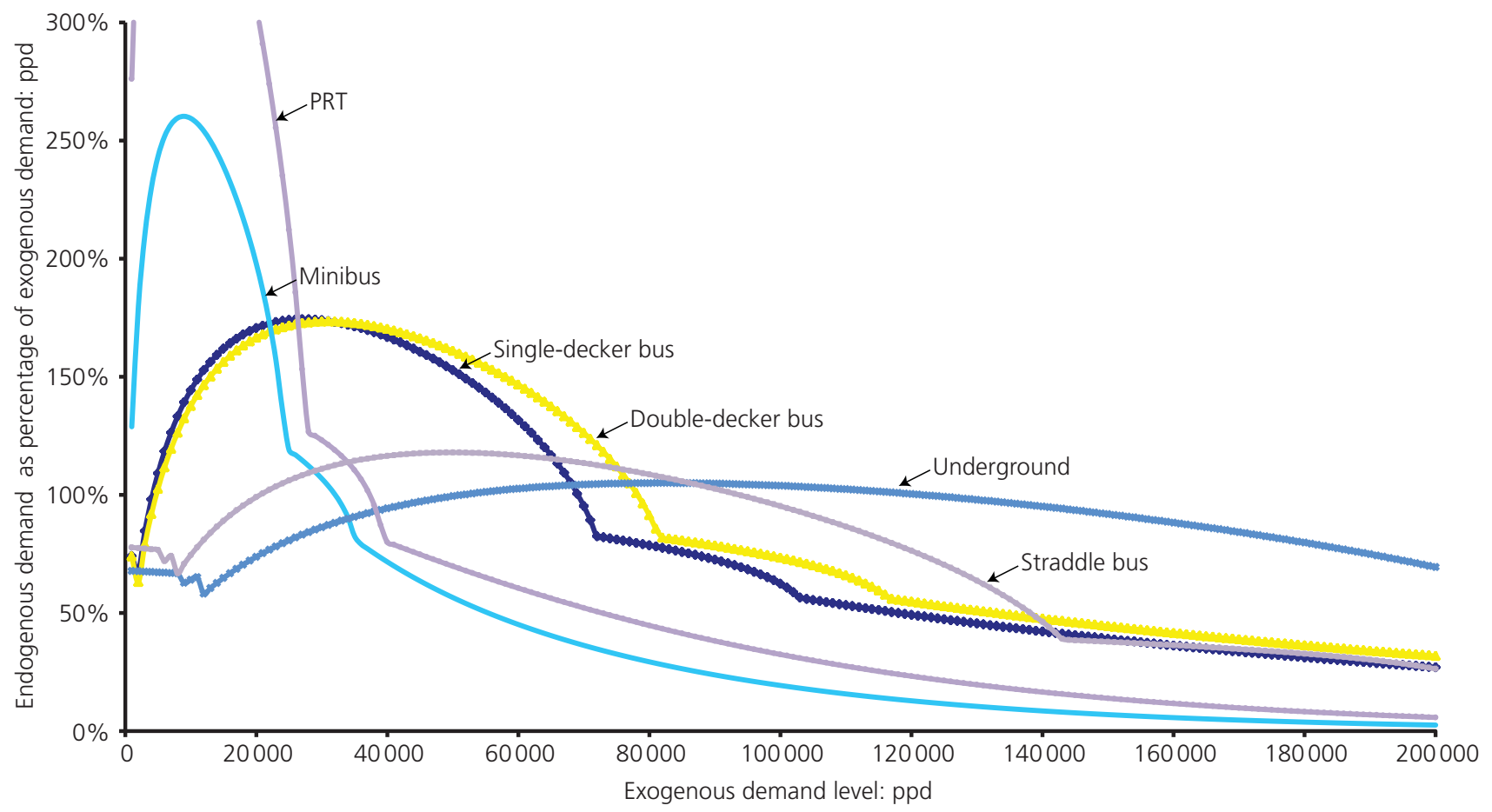

Figure 2. Relationship between endogenous demand and exogenous demand 
demand level, but it can still provide reasonable waiting and journey times with a high level of demand (from around 80000 ppd onwards) due to its high capacity and operational speed.

For all public transport technologies, the curves in Figure 2 exhibit some parabolic features as a result of the changing waiting and journey times at different demand levels. The waiting time decreases at low demand levels due to the increasing service frequency for increasing passenger numbers. However, increasing passenger demand would also cause more boarding/alighting time and thus more passenger waiting time. Therefore, an increasing trend for waiting time is shown when the time reduced by more service frequency is lower than the extra time passengers have to spend to wait for other people boarding/alighting. Journey times for all passengers increase with demand levels because speeds are reduced when more vehicles are on the road. As a result of changing waiting times and journey times, the curves in Figure 2 gradually increase until the passenger wait time reaches a minimum.

The result of this demand-supply relationship analysis shows how actual public transport performance affects passenger demand in reality. The actual passenger demand can then be substituted back to the average social and operator cost calculation.

\section{Key results from the model}

The spreadsheet model aims to produce a comparative view of public transport modes to illustrate their advantages for different demand levels. To indicate the relationships between costs and demand levels, the equations for average social cost and average operator cost are

$$
\begin{gathered}
A S C=\frac{T S C}{P K M} \\
A O C=\frac{T O C}{P K M}
\end{gathered}
$$

The average social cost and average operator cost for each public transport technology are calculated by using the total costs divided by passenger kilometres, which is related to the level of demand. The traffic simulated in the spreadsheet model uses passenger demand increasing step by step from $1000 \mathrm{ppd}$ to $200000 \mathrm{ppd}$ and the costs are also analysed based on this exogenous demand. The relationship between endogenous demand and exogenous demand has been demonstrated earlier, which would affect the actual social and operator costs.

Social and operator cost values are not sensitive just to changes in waiting time and in-vehicle time, but they are also sensitive to the actual number of passengers. After considering the elasticity of passenger waiting times and in-vehicle times, the endogenous level of demand for each public transport technology would change from the original level of demand to a different extent and the average costs would differ. By substituting the endogenous demand back into the model, the raw output graph shown in Figure 3 is obtained.

Note that, in Figure 3, the level of passenger demand on the $x$-axis is the endogenous demand obtained by using the model calculation in Section 3 and the average costs are recalculated based on this demand level. This graph shows the shape of the cost curve for the 16 public transport technologies, as well as the most feasible range for each public transport technology, are shown as the bottom of the U-shaped curves. However, many data points are overlapping, making it hard to identify each curve. Therefore, minimum cost graphs were produced for both average social cost (Figure 4) and average operator cost (Figure 5) to determine the public transport technology with the lowest cost for different endogenous demand levels.

Figure 4 shows that the minibus only shows the lowest average social cost when the daily demand is less than $2000 \mathrm{ppd}$ due to its low vehicle and infrastructure costs but having a vehicle capacity of only 16 people. When demand is higher than $2000 \mathrm{ppd}$, the lower investment but higher capacity advantages of conventional buses stand out by showing the lowest social costs in the graph. The straddle bus also shows great potential when the demand level is higher than $57000 \mathrm{ppd}$ - the higher capacity than normal buses, lower capital investment for vehicles and infrastructure than heavy rail and underground and the electric motive design lowering external costs make this technology achieve the lowest average social costs within the demand level range of 57000-101000 ppd. Underground technology has the highest default value capacity among all the public transport forms modelled. For demand above $101000 \mathrm{ppd}$, underground shows the lowest average social costs while the costs of almost all other public transport forms are extremely high as the number of vehicles required is more than the infrastructure capacity and congestion makes the user cost much higher. Figure 5 shows the most feasible public transport technologies considering only operator costs. The dominating ranges for each form of public transport are different compared with those in Figure 4. Public transport technologies with high capacity and low capital investment such as double-decker buses (from around $14000 \mathrm{ppd}$ to $57000 \mathrm{ppd}$ ) and suburban heavy rail (from around $58000 \mathrm{ppd}$ to $71000 \mathrm{ppd}$ ) stand out because less vehicle and infrastructure costs are required.

The effects of applying endogenous demand are shown clearly in the graphs. The curves in Figures 4 and 5 are discontinuous between the straddle bus and underground due to the endogenous demand. After reaching a demand level of $101000 \mathrm{ppd}$, the straddle bus becomes less attractive for passengers and the actual demand level falls. As a result, the average cost curve of the straddle bus terminates at that point to reflect the effect of endogenous demand, which also happens to other public transport technologies when their attractiveness is lower than the other 


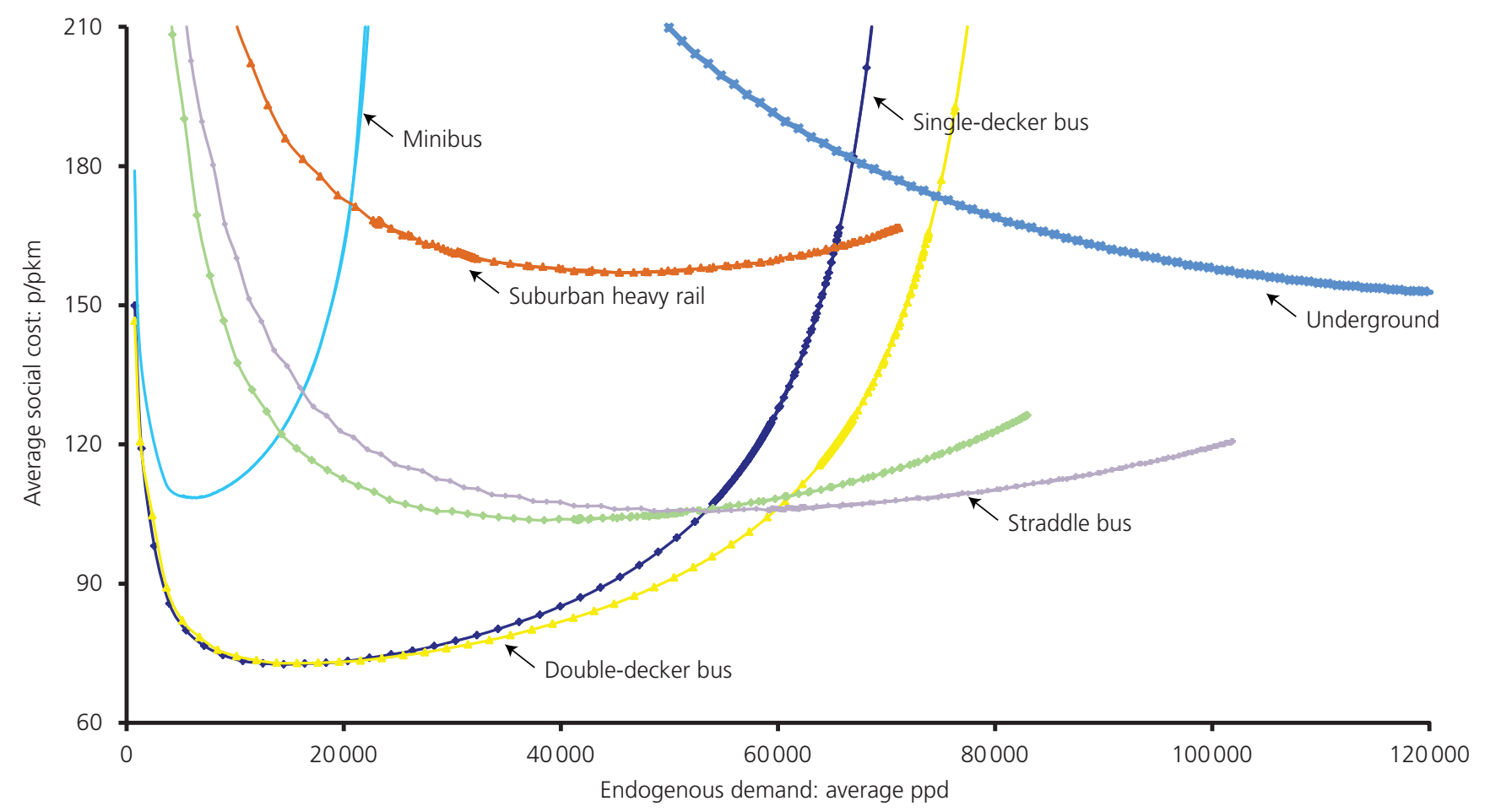

Figure 3. Average social costs after applying endogenous demand

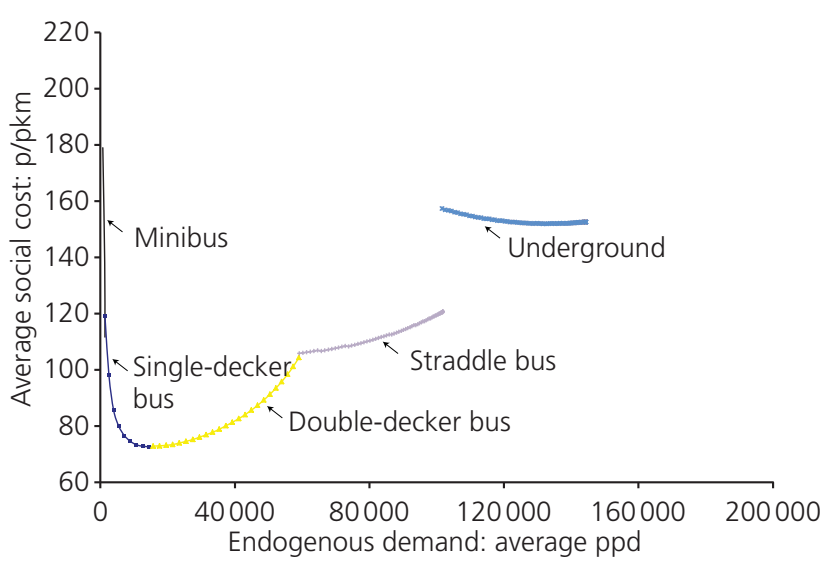

Figure 4. Minimum average social cost after applying endogenous demand

services. Although some public transport modes (e.g. conventional buses) reach a very high level of average cost, their waiting and in-vehicle times are still very competitive. As a result, passenger demand levels still grow when average costs increase dramatically. Vehicle capacity for each public transport technology can be input by the user or default values in the model can be used. These values are assumed to be fixed along the calculation for each technology. Therefore, the discontinuity in Figures 4 and 5 would be filled if the car units for rail modes increased, because of extra capacity and attractiveness. For example, if the assumed

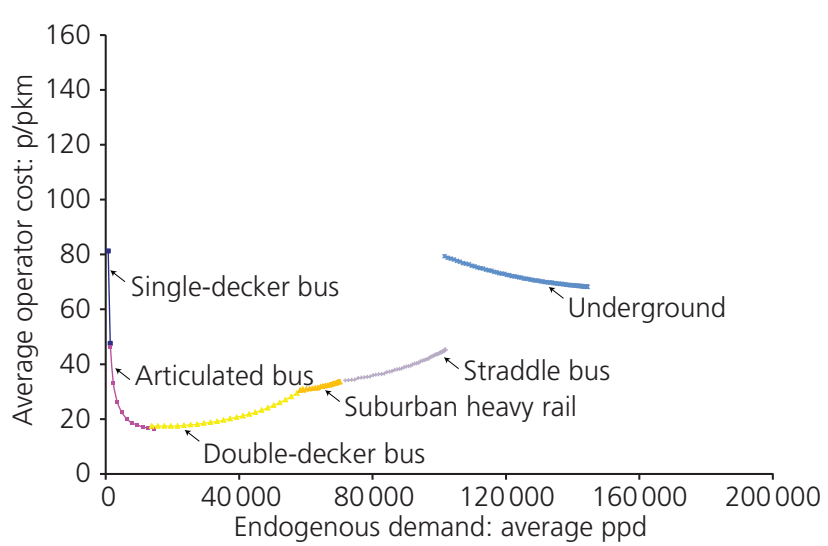

Figure 5. Minimum average operator cost after applying endogenous demand

car unit for suburban heavy rail is increased to a four-car unit, the gap between straddle bus and underground will be reduced and filled by the curve for suburban heavy rail.

The differences between average operator cost and average social cost are also demonstrated in Figures 4 and 5. The data indicate that total operator costs on a $12-\mathrm{km}$ route (including capital investment) account for between $1 / 5$ and $1 / 2$ of the total social costs, with the rest being user costs (such as journey time and walking time costs) and external costs (such as air pollution, 
noise pollution, climate change and accident costs). For heavy rail technologies, the operator costs account for more of the social costs when compared with conventional bus technologies. For example, the operator cost of the double-decker bus technology when average daily passenger demand reaches 30000 is 18.5 pence per passenger kilometre $(\mathrm{p} / \mathrm{pkm})$ while the average social cost is $90 \mathrm{p} / \mathrm{pkm}$. The operator cost for underground is $72 \mathrm{p} / \mathrm{pkm}$ at the 130000 daily demand level while the social cost is $170 \mathrm{p} / \mathrm{pkm}$. The main reason for this is that capital investments for infrastructure and vehicles for heavy rail technologies are much higher than for other public transport modes. The growth of passenger demand also has larger impacts on user costs such as waiting time and journey time.

Based on Figures 4 and 5, the public transport technology that gives the lowest average cost at a distinct demand level is the one that has the most suitable passenger carrying capacity for that demand level while user costs and non-user costs are reduced (e.g. using existing roads to reduce infrastructure costs, using hybrid power to reduce external costs, etc.). The public transport technologies that did not show a cost advantage in the graphs also have special characteristics to form an integrated public transport system. For example, PRT and minibuses could be used as a feeder service to the stations of other public transport systems or to link areas that are not served by buses or the underground (e.g. the PRT linking the business park to Heathrow terminal 5). The integrated relationships between different public transport modes could be a potential future development of this spreadsheet model by considering a network rather than a corridor.

\section{Conclusion and future work}

This paper has reviewed the spreadsheet model developed in the TEST project and improved the model by adding the straddle bus technology, updating cost tables and analysing the effect of endogenous demand. The example of analysing an innovative public transport technology (the straddle bus) demonstrates that the spreadsheet model can be used for strategic analysis at both the planning stage and the implementation stage. Parameter values in the model can be modified according to any update of resources to fit the characteristics of the selected public transport technology.

An investigation of the effects of endogenous passenger demand has been presented. Based on the spreadsheet model analysis, the public transport technology with the lowest social cost per passenger is the minibus for demand below 2000 passengers per day (ppd), the single-decker bus for demand from $3000 \mathrm{ppd}$ to $16000 \mathrm{ppd}$, the double-decker bus for $17000-57000 \mathrm{ppd}$, the straddle bus for 58 000-101000 ppd and underground for demand from $101000 \mathrm{ppd}$ to $144000 \mathrm{ppd}$ (this upper limit is for a six-car unit, which could increase to $180000 \mathrm{ppd}$ if increased to a twelve-car unit).

By considering the effect of actual service supplied, endogenous demand levels are calculated by using passenger waiting time and in-vehicle time elasticities. The upper limits for each public transport technology have been calculated to show at which point passengers would prefer to use other services because their waiting times and journey times provided are more attractive. These results are obtained by replacing fixed demand with endogenous demand and key differences occur when the attractiveness becomes lower than other public transport services. The infrastructure costs are relatively fixed for a public transport technology, the vehicle number required is associated with vehicle capacity and therefore the waiting time and the in-vehicle time would change for different demand levels. When the demand level is lower, conventional buses with low infrastructure and vehicle costs would be a better choice. When the demand level is higher, public transport modes with high passenger capacity (e.g. straddle bus or underground) would be the best option while other public transport technologies experience extremely congested road conditions. This investigation shows what would be the likely level of demand and average costs if the quality of public transport services changes.

Due to the size, location and other factors of different public transport corridors in different cities, demand levels will vary. The developed spreadsheet model can then help to assess choices. For example, the straddle bus was planned to have a trial operation in Mengtougou, western Beijing, where the demand level is approximately $50000-60000 \mathrm{ppd}$ but this was subsequently changed to light rail transit. This choice can be assessed from a social cost point of view by using the spreadsheet model, which, with the data used here, indicated that the straddle bus is worth pursuing in preference to light rail.

Further work on this model could focus on improvements by simulating operations of public transport modes (especially the newly invented straddle bus) in a selected urban area using the transportation analysis software Vissim. Microscopic simulations could be adopted to observe the characteristics of individual vehicles for different public transport technologies in an urban network in order to consider performance in mixed traffic flows. An urban area identified for simulation is the main corridor in Nanning, China, where passenger demand level is about 90000 $100000 \mathrm{ppd}$. The current government decision is to build an underground system to meet this high passenger demand. However, according to the spreadsheet model, the straddle bus would also be a competitive choice in that demand range. A complete traffic network could be built in future work to analyse the costs for all road users and compare different public transport technologies.

\section{REFERENCES}

Balcombe R, Mackett R, Paulley N et al. (2004) The Demand for Public Transport: A Practical Guide. TRL, Wokingham, UK, Report TRL593.

Brand C and Preston J (2001) Technical and Financial

Characteristics of Public Transport Systems. Transport

Studies Unit, University of Oxford, Oxford, UK, TSU

working paper 911 .

Brand C and Preston J (2002a) The Field Studies - Synthesis of 
Transport

Volume 168 Issue TR4
Reassessing the financial and social costs

of public transport

Li and Preston
Results. Transport Studies Unit, University of Oxford, Oxford, UK, TSU working paper 931.

Brand C and Preston J (2002b) The Wider Costs and Benefits of Urban Public Transport Systems. Transport Studies Unit, University of Oxford, Oxford, UK, TSU working paper 919.

Brand C and Preston J (2003a) The Software Tool: Specification and Case Study Validation. Transport Studies Unit, University of Oxford, Oxford, UK, TSU working paper 948.

Brand C and Preston J (2003b) Which technology for public transport? A review of system performance, costs and impacts. Proceedings of the Institution of Civil Engineers Transport 156(4): 201-210.

Brand C and Preston J (2006) TEST - A tool for evaluating strategically integrated public transport. Proceedings of European Transport Conference, Strasbourg, France. See http://abstracts.aetransport.org/paper/index/id/2429/confid/12 (accessed 11/03/2015).

Currie G and Wallis I (2008) Effective ways to grow urban bus markets - a synthesis of evidence. Journal of Transport Geography 16(6): 419-429.

Daugherty GG, Astrop AJ and Balcombe RJ (1999) A Comparative Assessment of Major Bus Priority Schemes in Great Britain. TRL, Wokingham, UK, Report TRL409.

DfT (Department for Transport) (2012) Transport Statistics Great Britain 2012. See https://www.gov.uk/government/ publications/transport-statistics-great-britain-2012 (accessed 26/06/2013).

Jakob A, Craig JL and Fisher G (2006) Transport cost analysis: a case study of the total costs of private and public transport in Auckland. Environmental Science \& Policy 9(1): 55-66. See http://linkinghub.elsevier.com/retrieve/pii/ S146290110500136X (accessed 13/10/2011).

Jansson JO (1980) Transport System Optimisation and Pricing. Economic Research Institute, Stockholm, Sweden.

Knowles RD (2007) What future for light rail in the UK after ten year transport plan targets are scrapped? Transport Policy 14(1): 81-93.

McDermon D (2010) Riding High: A Chinese Concept for Bus Transit. New York Times, 8 August. See http://wheels.blogs. nytimes.com/2010/08/05/riding-high-a-chinese-concept-forbus-transit/ (accessed 01/03/2012).

Meyer JR, Kain JF and Wohl M (1965) The Urban Transportation Problem. Harvard University Press, Cambridge, MA, USA.

Nash CA (1988) Integration of public transport: an economic assessment. In Bus Deregulation and Privatisation. (Dodgson JS and Topham N (eds)). Gower, Avebury, UK, pp. 99-118.

NERA, AEA Technology Environment and TRL (1999) Report on Phase 2 of the Study into Lorry Track and Environmental Costs. NERA, London, UK. See http://www.fta.co.uk/export/ sites/fta/_galleries/downloads/haulage_industry_task_group/ nera_report.pdf ((accessed 11/03/2015).

NGT (New Generation Transport) (2014) See www.ngtmetro.com (accessed 22/01/2015).

OECD (Organisation for Economic Co-operation and Development) (2011) Purchasing Power Parities (PPPs)
Data. See http://www.oecd.org/document/47/ 0,3746,en_2649_34347_36202863_1_1_1_1,00.html (accessed 31/03/2012).

ONS (Office for National Statistics) (2011) CPI and RPI Detailed Reference Tables. See http://www.ons.gov.uk/ons/publications/ re-reference-tables.html?edition $=\mathrm{tcm} \% 3 \mathrm{~A} 77-223807$ (accessed 15/01/2012).

Ricci A and Friedrich R (1999) Calculating Transport Environmental Costs: Final Report of the Expert Advisors to the High Level Group on Infrastructure Charging. European Commission, Brussels, Belgium. See http:// www.ocs.polito.it/biblioteca/mobilita/CalculatingCosts.pdf (assessed 12/08/2012).

Preston J and James T (2000) Analysis of Demand for Bus Services. Transport Studies Unit, University of Oxford, Oxford, UK, Final report.

Sadieblooming (2010) China Straddling Bus. See http:// www.youtube.com/watch?v=Hv8_W2PA0rQ (accessed 13/12/2010).

Sansom T, Nash C, Mackie P, Shires J and Watkiss P (2001) Surface Transport Costs and Charges: Great Britain 1998. Institute for Transport Studies, University of Leeds and AEA Technology Environment, Report commissioned by the Department of Environment, Transport and the Regions.

SDG (Steer Davies Gleave) (1999) ATOC - Railtrack Literature Review. London Transport Buses. SDG, London, UK.

Small KA (1992) Urban Transportation Economics. Harwood Academic, Chur, Switzerland.

Tirachini A, Hensher DA and Jara-Díaz SR (2010) Comparing operator and users costs of light rail, heavy rail and bus rapid transit over a radial public transport network. Research in Transportation Economics 29(1): 231-242.

ULTraGlobalPRT (2011) ULTra at London Heathrow Airport. See http://www.ultraprt.com/heathrow/ (accessed 28/03/2012). 